\title{
FASILITAS PENGOLAHAN HASIL PERTANIAN DAN PETERNAKAN
}

\author{
Mochammad Tegar Alexander
}

Program Studi S1 Arsitektur, Fakultas Teknik, Universitas Tarumanagara, mtegaralexander@gmail.com

\begin{abstract}
Abstrak
Indonesia adalah negara agraris, dimana sebagian besar penduduknya bermata pencaharian di bidang pertanian. hingga kini, mayoritas penduduk Indonesia memanfaatkan alam untuk menunjang kebutuhan hidupnya dan salah satunya dengan menggantungkan hidup pada sektor pertanian. Banyaknya lahan pertanian biasanya dapat ditemui di daerah peri kota, salah satunya yang akan dibahas disini yaitu Kabupaten Karawang, salah satu daerah di peri kota dengan luas lahan pertanian yang sangat tinggi. Karawang telah mengalami krisis pada sektor pertaniannya beberapa tahun ini, penyebab utamanya yaitu karena pengalihan lahan dan musibah banjir yang menyebabkan menurunnya hasil produksi pertanian mereka. Satu proyek arsitektur memang tidak bisa menyelesaikan permasalahan banjir, ataupun menyelesaikan permasalahan berkurangnya lahan pertanian yang ada pada satu kota, namun kita masih tetap bisa membantu walau hanya dengan cara menjadi contoh bagi masyarakat sekitar, bahwa ada jalan keluar dan cara lain agar hasil produksi pertanian masih bisa optimal walaupun lahan pertanian berkurang. Dalam tulisan jurnal ini, akan dibahas bagaimana arsitektur bisa berkontribusi menyelesaikan permasalahan krisis pertanian yang terjadi di daerah Karawang, dengan memunculkan sebuah gagasan dalam bentuk bangunan arsitektur yang dapat menjadi salah satu jalan keluar penyelesaian masalah pertanian ini.
\end{abstract}

\section{Kata kunci: agraris; Banjir; Pertanian Karawang}

\begin{abstract}
Indonesia is an agrarian country, where most of the population lives in agriculture. Even until now, most of Indonesia's population uses nature to support their needs and one of them is by depending on the agricultural sector. Many agricultural lands can usually be found in peri-urban areas, one of which will be discussed here is Karawang Regency, one of the areas in peri-urban areas with a very high agricultural land area. Karawang has had a crisis in its agricultural sector in recent years, the main reason being land usage change and flood that caused their production value and number to decrease drastically. An architectural project cannot solve the flood problem, or solve the shortage of agricultural land in one whole city. But we can still help even if it is only by being an example for the surrounding community, that there is always a way out, so that agricultural production can still be optimal even though agricultural land is reduced. In this journal paper, we will discuss how to solve the crisis problem that occurred in the Karawang area, by bringing up an idea in the form of an architectural building that can be a way out of solving this agricultural problem.
\end{abstract}

\section{Keywords: agrarian; Flood; Karawang Farm}

\section{PENDAHULUAN}

\section{Latar Belakang}

berkurangnya ketersediaan lahan adalah salah satu isu yang meresahkan bagi sektor pertanian, dikarenakan semakin bertambahnya jumlah manusia yang menyebabkan lahan pertanian harus dialih fungsikan menjadi lahan permukiman. Jika seperti ini terus, maka lama kelamaan lahan yang tersedia tidak akan cukup untuk memenuhi kebutuhan pangan masyarakat. Ditambah lagi masalah banjir yang sering melanda Karawang, yang menggenangi dan merusak hasil pertanian yang ada. 
Lahan yang dibutuhkan pertanian sangatlah luas, tercatat pada tahun 2016 lahan pertanian di karawang mencapai luas 200,168 hektare. Namun walau pertanian ini merupakan tempat tumbuhnya tanaman hijau, bukan berarti merupakan area resapan air. Jika lahan seperti itu membentang luas di daerah Karawang, tentu akan menjadi salah satu penyebab banjir yang kerap terjadi.

\section{Rumusan Permasalahan}

Setelah ditelaah, Permasalahan muncul dikarenakan lahan yang dibutuhkan untuk pertanian sangatlah luas. Dari peta persebaran lahan pertanian, terlihat penyebran dan luas pertanian(warna biru) yang ada. inilah yang menyebabkan maraknya peralihan lahan dan banjir yang terjadi.
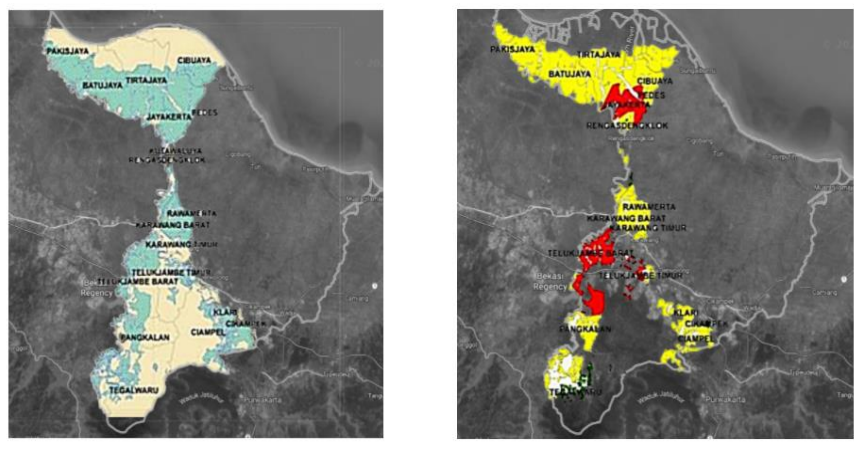

Gambar 1. Peta Persebaran Pertanian(Kiri) dan Banjir(Kanan) di Karawang Sumber:pemetaan bahaya banjir lahan sawah di kabupaten karawang, 2021

Dari persebaran banjir, terbukti bahwa banjir hanya melanda lahan pertanian. Mengapa ini bisa terjadi? Memang lahan pertanian merupakan tempat tumbuhan hijau ditanam, namun tetap saja lahan ini bukanlah lahan yang baik untuk menjadi area resapan, sehingga tidak bisa menghadang banjir yang datang.

Jika masalah utamanya adalah lahan pertanian yang terlalu luas, maka pertanyaannya adalah bagaimana caranya kita mengurangi besarnya kebutuhan lahan pertanian, tapi masih bisa memproduksi beras dengan efektif?

Dahulu, manusia pernah mengalami masalah yang serupa dengan kasus ini, yaitu kurangnya lahan yang tersedia untuk permukiman manusia. Manusia menyelesaikan permasalahan ini dengan membuat permukiman didalam bangunan bertingkat. Lahan yang dibutuhkan tentu lebih sedikit daripada permukiman tradisional yang dibangun secara horizontal, tetapi dapat memenuhi banyaknya kebutuhan manusia akan tempat tinggal. Tidak hanya permukiman, bangunan dengan berbagai fungsi lain seperti kantor, pasar, supermarket, juga telah menerapkan pembangunan secara vertikal untuk menyelesaikan permasalahan kebutuhan lahan. Lalu kalau begitu, mengapa kita tidak mencoba untuk membangun pertanian secara vertikal?

Lalu selanjutnya muncul sebuah pertanyaan lain. Jika kita sudah berhasil membuat pertanian vertikal dan menyelesaikan masalah ini, bagaimana dengan masalah kebutuhan lahan untuk fungsi lainnya yang menjadi masalah di daerah Karawang?

Wayan Dipta (dalam, Danag Firmanto, 2016) menjelaskan bahwa Indonesia masih mengimpor sekitar 80 persen bahan baku susu dari total kebutuhan nasional. "Produksi susu segar dalam negeri semakin menurun, sementara permintaan terus meningkat,". Menurut Wayan, masalah penurunan produksi susu dipengaruhi oleh sulitnya pakan hijau untuk sapi. 
Lalu jika kita berhasil menyelesaikan masalah kebutuhan lahan pertanian, dan kebutuhan lahannya sudah menurun, apakah selanjutnya lahan di Karawang akan habis oleh kebutuhan fungsi peternakan?

Apakah ada sebuah gagasan arsitektur yang bisa membantu menyelesaikan seluruh masalah ini demi kepentingan masyarakat Karawang?

\section{KAJIAN LITERATUR}

\section{Vertical Farming}

Pertanian vertikal adalah praktik menanam tanaman pada medium yang berlapis dan ditumpuk secara vertikal, sehingga tumbuhan yang bisa ditanam jauh lebih banyak dibanding teknik penanaman tradisional. Tujuan utamanya adalah untuk mengoptimalkan hasil produksi seefektif munkgin. ada tiga teknik pertanian vertikal yang sering digunakan, yaitu hidropinik, akuaponik dan aeroponik.

\section{Hydroponic}

Hidroponik adalah salah satu teknik vertical farming, dengan mencelupkan tanaman pada air yang didalamnya sudah larut nutrisi untuk tanaman. cara ini sangat bagus karena air yang digunakan bisa terus dirotasi dan digunakan berulang kali sehingga sangat menghemat penggunaan air.

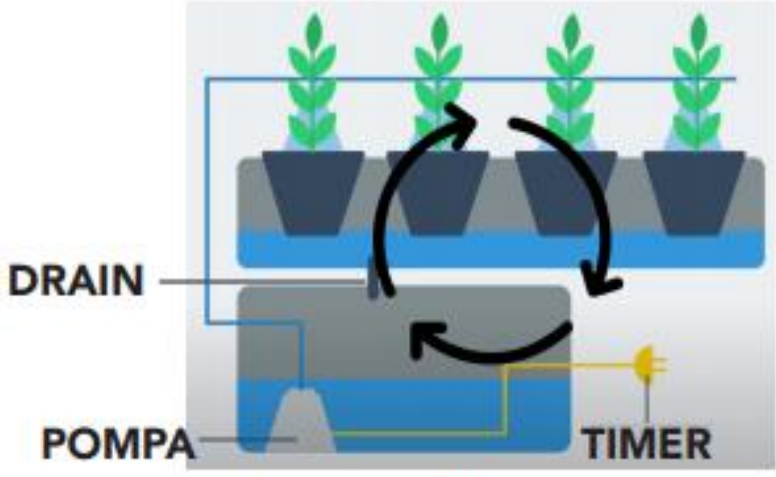

Gambar 2. Sistem Hidroponik

Sumber:youtube.com, 2021

Aquaponics

Teknik vertical farming, dengan menaruh ikan pada tangki air. air berisikan kotoran ikan ini baik untuk nutrisi tanaman, dan lalu akan disalurkan melalui pipa dan ke seluruh tanaman yang ada. Air kotoran ikan tersebut lalu akan tersaring dan disalurkan kembali ke kolam ikan.

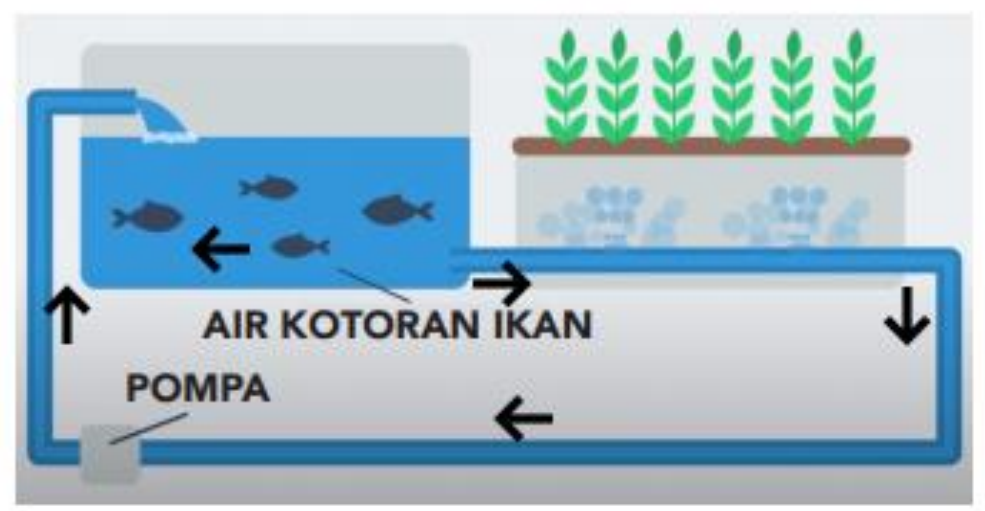

Gambar 3. Sistem Akuaponik Sumber:youtube.com, 2021 


\section{Aeroponics}

Salah satu teknik yang digunakan dalam vertical farming, dimana pasokan air untuk tanaman berasal dari uap air yang berisi nutrisi. Studi membuktikan bahwa cara ini bisa mengurangi $90 \%$ penggunaan air.

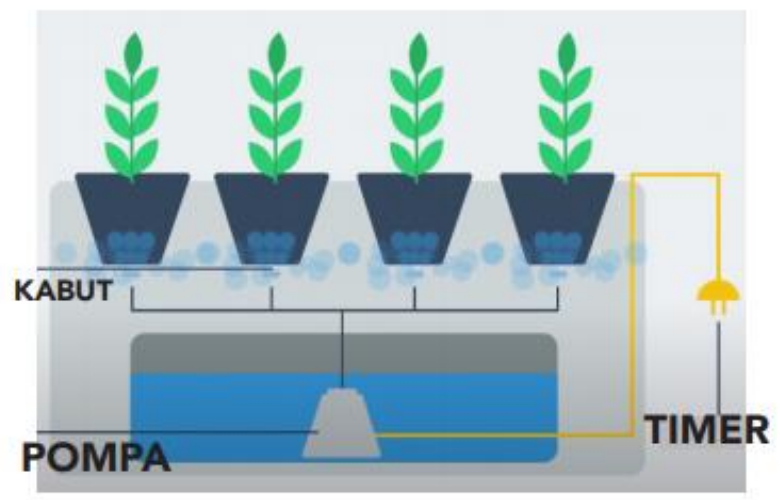

Gambar 4. Sistem Aeroponik

Sumber:youtube.com, 2021

Peternakan Sapi Perah

Dalam pemeliharaan dan pembibitan sapi perah, banyak hal yang perlu diperhatikan untuk keperluan sapi perah. Kebutuhan itu meliputi, kandang sapi, tempat pengembang biakkan, kandang karantina untuk sapi yang sakit, lapagan hijau terbuka untuk dikeparnya sapi, ruang penyimpanan Jerami untuk makanan sapi, ruang pengolahan limbah, ruang pemerahan sapi, sirkulasi yang baik untuk sapi, serta ruang produksi susu sapi.

\section{METODE}

\section{Learning the Rules}

Untuk merancang sebuah peternakan dan pertanian, hal pertama yang harus dilakukan adalah mempelajari seluruh kaidah dan aturan yang ada tentang peternakan dan pertanian. Salah satu cara yang bisa digunakan untuk mempelajari hal ini adalah dengan mengumpulkan data literatur, baik dari jurnal lain, buku maupun artikel dari internet. Setelah mempelajari semua literatur yang saya kumpulkan, saya mulai mengurutkan proses kerja yang harus dilakukan untuk mendesain bangunan peternakan dan pertanian vertikal.

Untuk bangunan pertanian vertikal, saya harus menentukan jarak tanam yang akan digunakan, besarnya ubinan pada pertanian vertikal ini, lalu menghitung hasil produksi dari pertanian vertikalnya. Setelah itu akan saya desain ruangan ruangan yang diperlukan untuk produksi beras.

Untuk bangunan peternakan saya harus mencatat seluruh keperluan ruangan yang dibutuhkan dalam peternakan sapi perah, agar bangunan yang dihasilkan dapat memenuhi standar untuk pemeliharaan dan produksi sapi perah. Selain mempelajari kebutuhan fungsi peternakan sapi perah, saya juga mempelajari luasan standar yang diperlukan setiap ruang dari referensi denah peternakan sapi perah yang sudah terbangun dan nyata.

\section{DISKUSI DAN HASIL}

\section{Bangunan Pertanian}

\section{Menentukan Luas Petak}

Dalam buku "Teknik Ubinan Pendugaan Produktifitas Padi Menurut Sistem Tanam" 2017. Produktifitas padi paling efektif adalah dengan menggunakan jarak tanam $20 \mathrm{~cm} \times 20 \mathrm{~cm}$, hingga paling tinggi yaitu $30 \mathrm{~cm} \times 30 \mathrm{~cm}$. Jarak tanam padi yang akan digunakan dalam proyek ini adalah adalah $25 \mathrm{~cm} \times 25 \mathrm{~cm}$. 

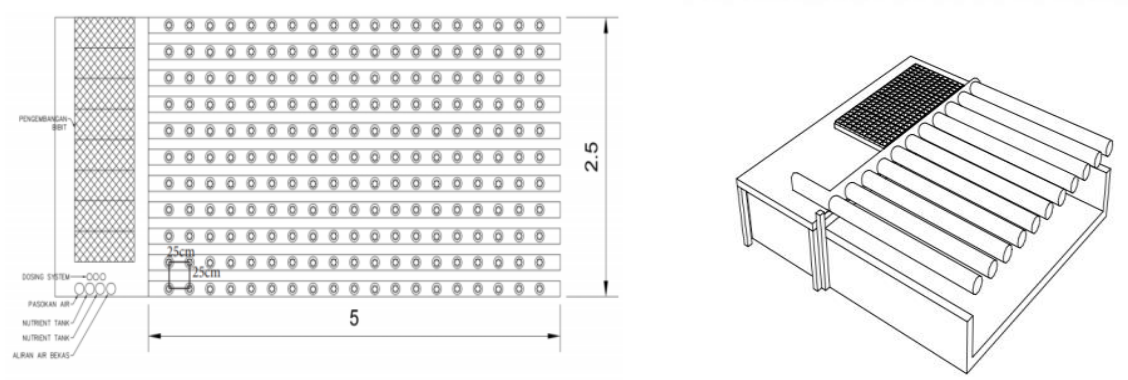

Gambar 5. Desain Instalasi Petak Pertanian Vertikal Sumber:Data Pribadi, 2021

\section{Menentukan Peletakan Petak Pertanian}

Setelah menentukan luas petak, langkah selanjutnya adalah untuk meletakkan petak tersebut dalam bangunan, agar kita bisa melihat seberapa banyak yang bisa kita taruh dalam bangunan. Pada tahap ini saya menggunakan aplikasi Sketchup untuk membuat simulasi peletakan petak pada desain bangunan yang saya buat.

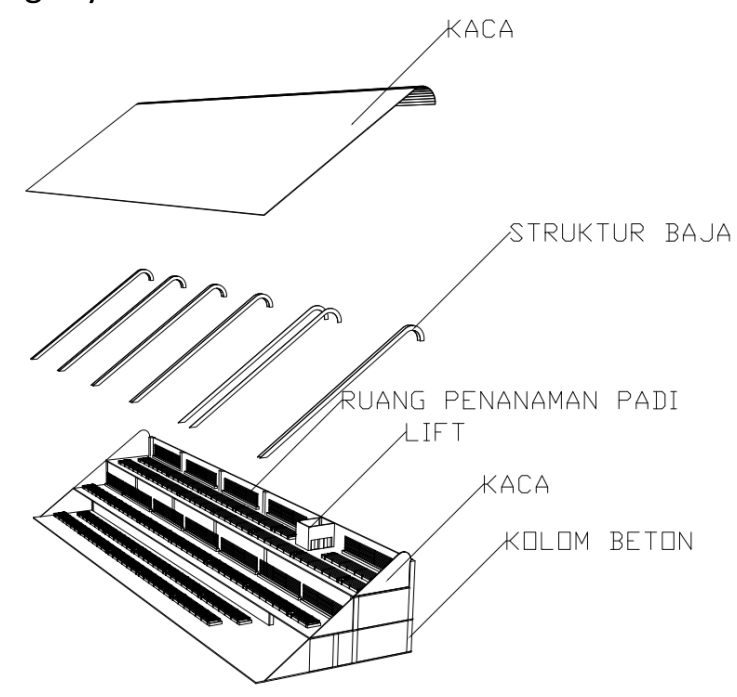

Gambar 6. Aksono Eksplode Bangunan Pertanian Vertikal Sumber: Data Pribadi, 2021

\section{Menghitung Perkiraan Hasil Panen}

Saya menghitung perkiraan hasil panen dengan cara menghitung empat faktor penting. yaitu dengan rumus: (jumlah rumpun per $\mathrm{Ha}$ ) $\mathrm{x}$ (jumlah anakan) $\mathrm{x}$ (jumlah bulir) $\mathrm{x}$ (berat per 1000 bulir)

Hitungan Luasan area pertanian:

Jarak tanam: $25 \times 25 \mathrm{~cm}$

Berarti per $0.0625 \mathrm{~m} 2$ ada 4 rumpun

1 Petak $2.5 \times 5 \mathrm{~m}=209$ Rumpun

Total Petak yang diletakan dalam bangunan: 120 Petak

120 petak $\times 209=25080$ rumpun

Anakan per rumpun $=1$

Bulir per malai $=$ kurang lebih 120 bulir

Berat per 1000bulir $=30$ gram $/ 1000$ (rata rata standar) 
Rumpun per $\mathrm{Ha}$

Lahan tersedia $=2400 \mathrm{M} 2$

Petak per $\mathrm{Ha}=120 \times 4=480$

Rumpun per petak $=209$

Rumpun per $\mathrm{Ha}=480 \times 209=100320$ Rumpun

$100320 \times 12 \times 125 \times 30 / 1000$

$4514400 \mathrm{Gram} / \mathrm{Ha}=4514,4 \mathrm{KG} / \mathrm{Ha}$

$=4,5$ ton $/ \mathrm{Ha} \mathrm{GKP}$

Konversi GKP ke GKG dan GKG ke Beras

Nilai konversi tiap provinsi berbeda-beda, untuk Provinsi Jawa Barat pada tahun 2012 nilai konversi GKP ke GKG adalah 82,00\% sedangkan konversi GKG ke beras 62,74 (tahun 2007).

\section{4,5 ton/Ha GKP x 82\% = 3,7 Ton GKG}

Produksi Beras $=20,7 \times 67,24 \%=2.5$ Ton per hektare

\section{Bangunan Peternakan Sapi Perah}

Zonasi

Bangunan peternakan saya bagi menjadi tiga bagian pada gubahannya, yaitu area pertama yang diperuntukkan untuk kandang sapi dan seluruh kebutuhan ruang yang dibutuhkan untuk tempat tinggal sapi. Area kedua yang diperuntukkan untuk ruang hijau terbuka tempat dikeparnya sapi. Area ketida yang diperuntukkan untuk kegiatan produksi susu, mulai dari pemerahan susu hingga proses pengolahan susu.

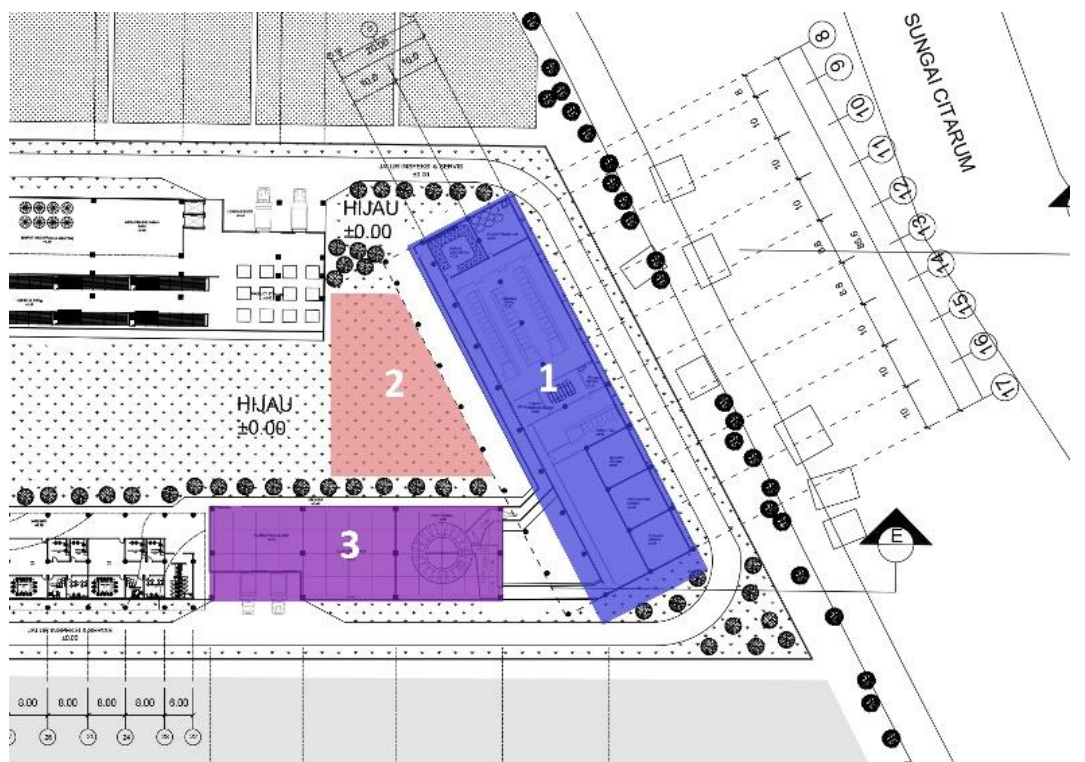

Gambar 7. Zonasi area peternakan \& produksi sapi perah Sumber:Data Pribadi, 2021

Kandang Ternak

Area untuk kandang yang disiapkan memiliki luas $1712 \mathrm{~m}^{2}$. Ruang pertama yang saya susun kedalam bangunan adalah kandang untuk sapi. Kapasitas bangunan memiliki ruang yang cukup untuk empat puluh sapi ternak. Lalu ruang kedua adalah ruangan untuk pengembang biakan sapi, bersamaan dengan klinik hewan didalamnya. Disebelah klinik hewan, tapi masih terpisah 
dengan kandang pengembang biakan, adalah kandang karantina untuk sapi yang sakit, agar terpisah dan tidak menularkan penyakit ke sapi lain. Lalu selanjutnya adalah disediakannya ruangan untuk gudang Jerami, dan terpisah dengan gudang Jerami adalah gudang untuk penyimpanan dan pengolahan limbah. Lalu didepannya adalah ruang hijau terbuka berukuran $1100 \mathrm{~m}^{2}$, tempat dikeparnya hewan ternak

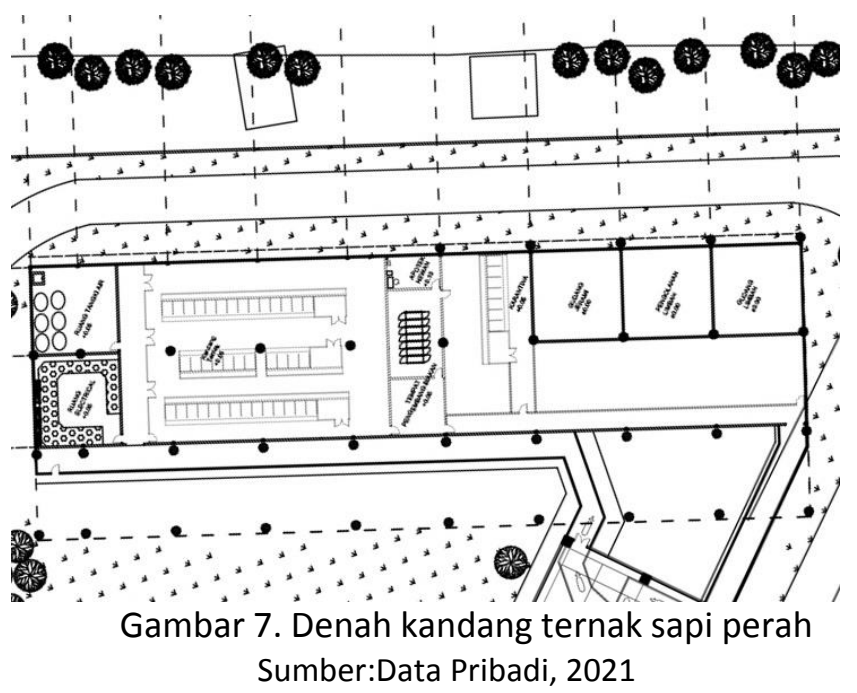

Ruang Produksi Susu

Ruang pertama yang harus saya perhatikan adalah ruang pemerahan susu sapi, karena ruangan ini harus berdekatan dan memiliki sirkulasi yang nyaman untuk keluar masuknya sapi. Baru setelah ini bisa di susun ruangan untuk pengolahan dan produksi susu sapi, beserta ruang untuk packing dan loading area.

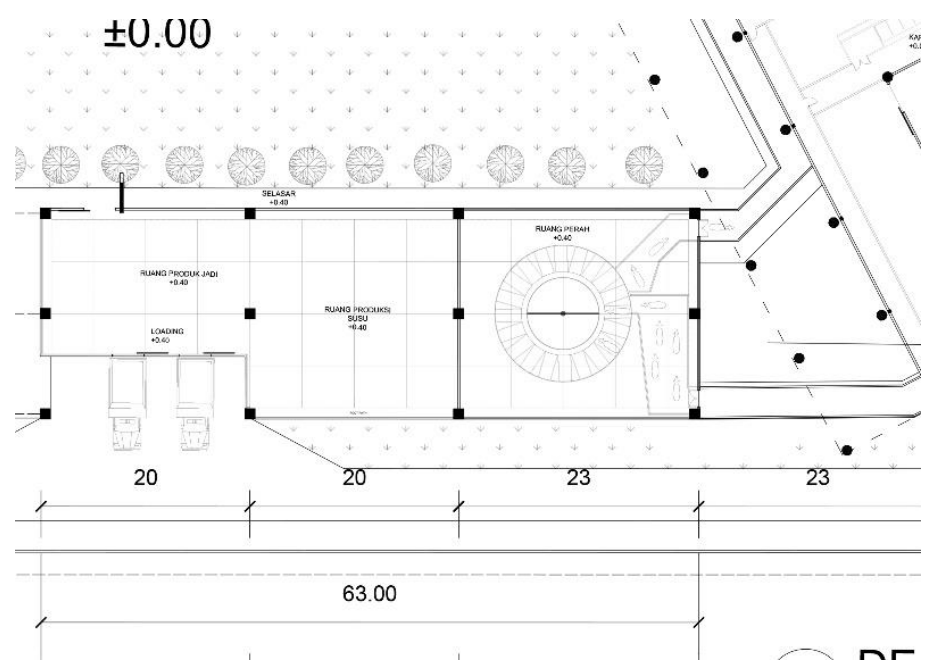

Gambar 7. Denah ruang produksi susu sapi

Sumber:Data Pribadi, 2021

\section{Program Ruang}

Program ruang yang saya susun berasal dari pemikiran menggabungkan beberapa komponen kehidupan yang ada pada alam sekitar kita ke dalam sebuah proyek, yang nantinya hubungan antara satu komponen dan komponen lainnya akan berkaitan satu sama lain dan menciptakan simbiosis mutualisme. 


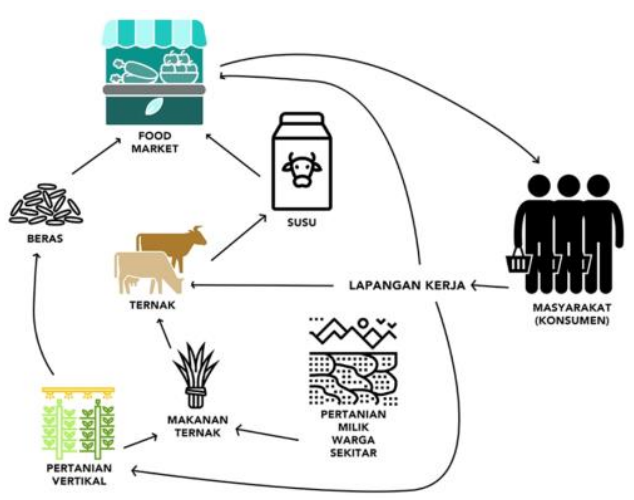

Gambar 7. Skema sederhana hubungan tiga komponen kehidupan dalam tapak Sumber:Data Pribadi, 2021

Ketiga komponen yang akan ada didalam tapak yaitu tumbuhan, manusia dan hewan. komponen tumbuhan berada pada fungsi pertanian vertikal sebagai produksi beras yang dapat dijual ke food market yang ada dalam tapak. Masyarakat sekitar juga bisa menggunakan fasilitas pengolahan padi ini untuk mengolah hasil panen mereka. Jerami bekas dari hasil produksi beras bisa menjadi makanan untuk komponen hewan, yang merupakan peternakan sapi perah.

Komponen manusia pada proyek ini yaitu berupa food market yang fungsinya dibagi menjadi dua, yaitu food market yang berupa UMKM dimana masyarakat bisa membuka usaha mereka sendiri, dan food market yang berupa pasar swalayan.

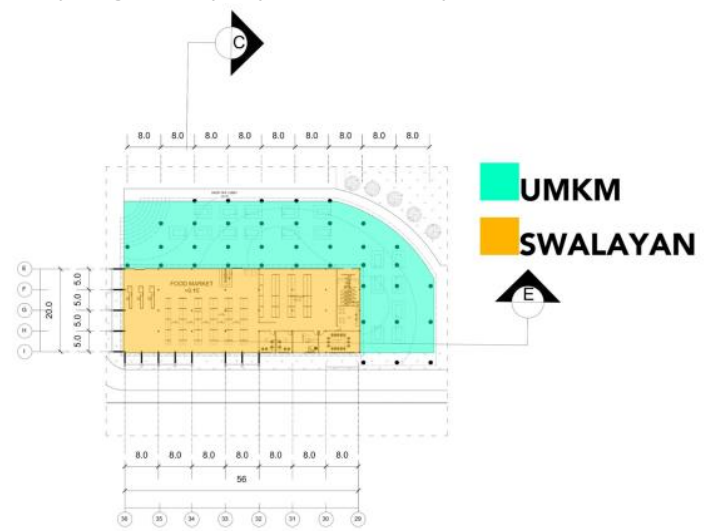

Gambar 8. Pembagian peruntukkan ruang market untuk UMKM dan Swalayan Sumber: Data Pribadi, 2021

Namun sangat disayangkan jika komponen manusia pada tapak ini hanya berupa food market dan area perkantoran dimana mereka bekerja. Maka dari itu saya mendesain sebuah roof garden pada area food market sebagai ruang hijau terbuka dimana pengunjung bisa melihat keseluruhan tapak dari atasnya.

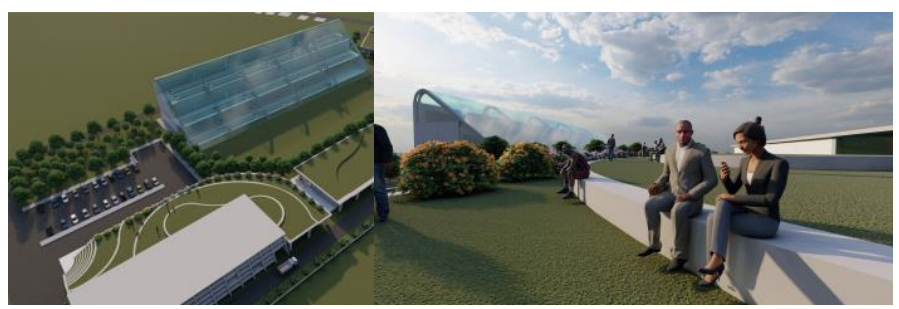

Gambar 9. Gambar Perspektif Roof Garden Pada Food Market Sumber: Data Pribadi, 2021 


\section{Proses Produksi Padi}

Ruangan produksi yang disediakan dalam bangunan pertanian dan produksi beras, menyesuaikan dengan seluruh kebutuhan yang diperlukan untuk mengolah padi. Proses pengolahan padi dimulai dari proses pemisahan bulir dari malainya, disini malai bekas dapat diolah dan digunakan untuk makanan ternak sapi. Setelah proses pemisahan, bulir padi akan dikeringkan di ruang pengeringan menggunakan alat blower yang menghasilkan udara panas yang dibutuhkan untuk mengeringkan padi. Lalu bulir yang kering akan disalurkan ke tempat penampungan untuk padi kering. Bulir padi yang sudah siap akan disalurkan ke proses milling dimana beras akan dipisahkan dari kulitnya. Melalui proses ini juga akan memisahkan antara bulir yang sempurna dan bulir yang hancur, dimana bulir yang hancur nantinya bisa digunakan untuk produksi sereal atau minuman fermentasi. Lalu ada juga pasar untuk peminat beras yang tidak digiling (tidak dipisahkan kulitnya).

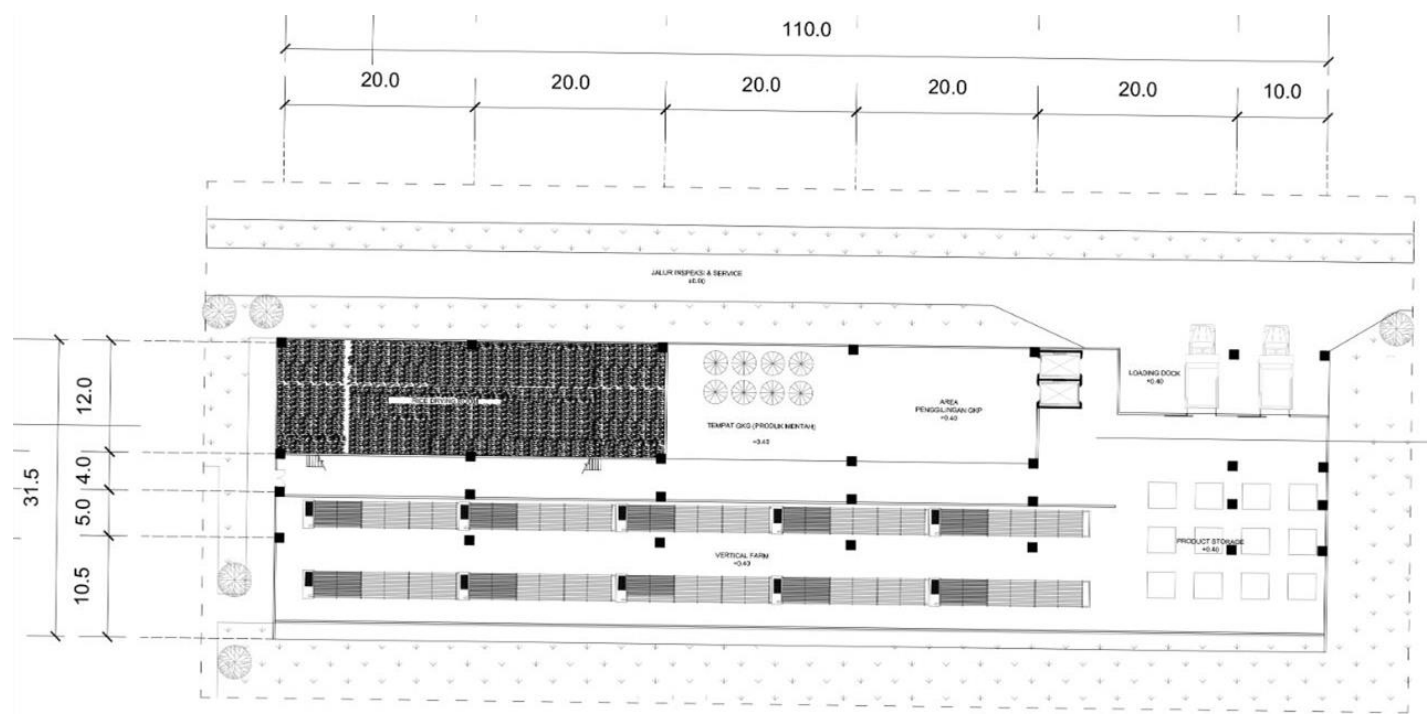

Gambar 10. Denah Lantai 1 Bangunan Pertanian \& Produksi Beras Sumber: Data Pribadi, 2021

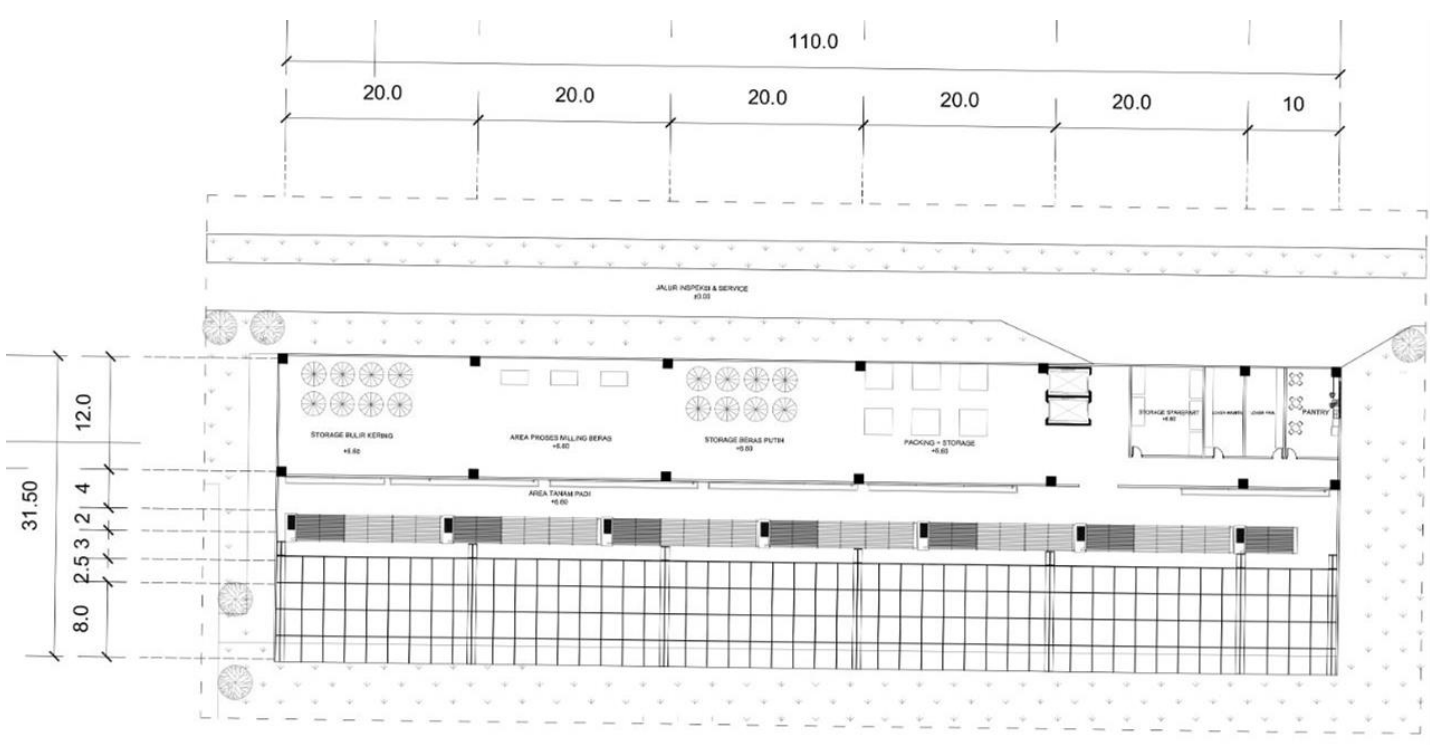

Gambar 11. Denah Lantai 2 Bangunan Pertanian \& Produksi Beras Sumber: Data Pribadi, 2021 


\section{Area Peternakan}

Area Peternakan berisikan ruang kandang untuk ternak yang bisa menampung 40 sapi. Lalu tempat pengembang biakkan sapi, tempat sapi melahirkan, yang diletakkan di samping ruang apotek hewan. lalu tidak jauh dari ruang apotek hewan, namun masih tetap terpisah dengan kandang pengembang biakan, terdapat kandang karantina untuk sapi yang terjangkit penyakit. Disediakan juga gudang untuk limbah dan pengolahan limbah. Akses kandang sapi juga terhubung dengan ruang pemerahan susu sapi. Di depan bangunan kandang ternak terdapat lapangan hijau terbuka untuk sapi.

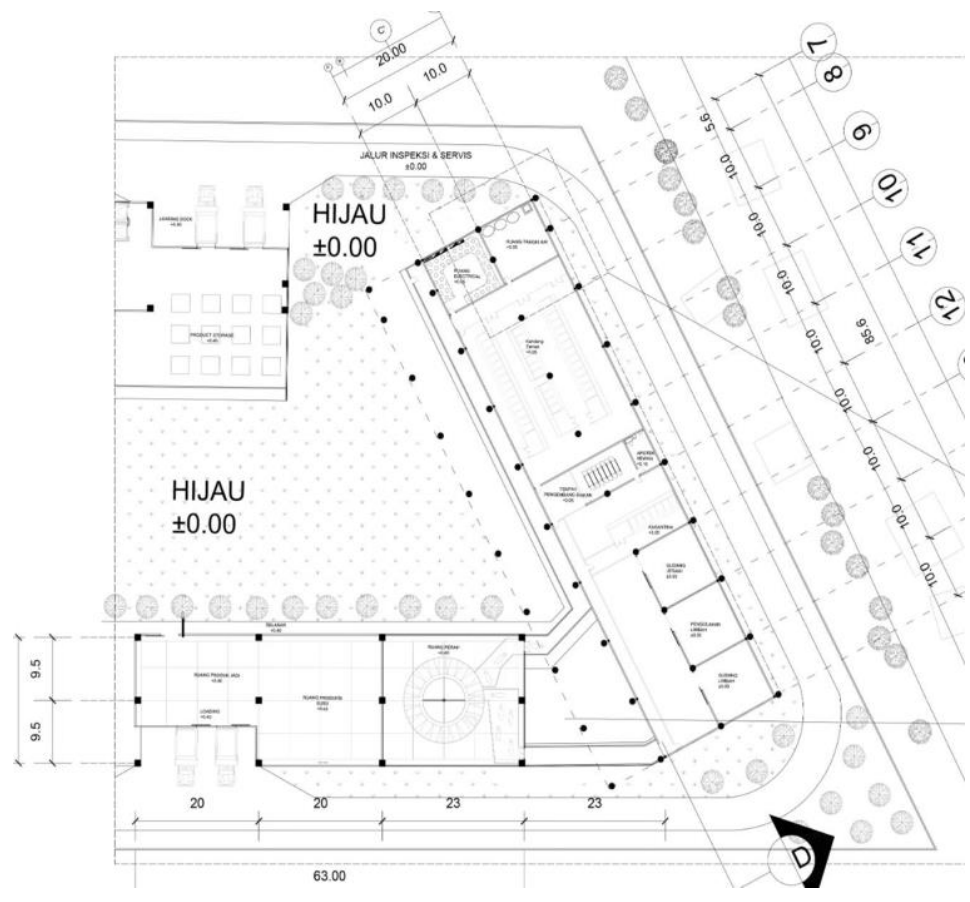

Gambar 12. Denah Bangunan Peternakan \& Produksi Susu Sumber: Data Pribadi, 2021

\section{Area Kantor}

Area kantor diperuntukkan untuk manajer dan seluruh staff pengelola, yang diletakkan di tengah tapak agar aksesibilitas mudah.
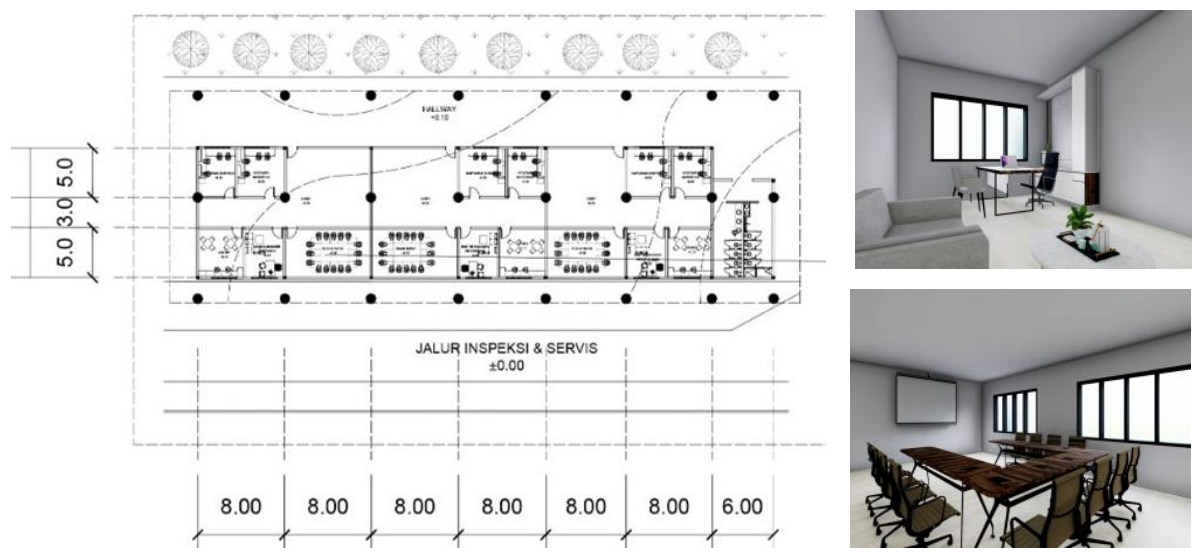

Gambar 13. Gambar Denah Area Kantor \& Perspektif Interior Kantor Sumber: Data Pribadi, 2021 


\section{KESIMPULAN DAN SARAN}

\section{Kesimpulan}

Dalam hidup kita harus bisa menyesuaikan diri dengan seluruh kondisi yang ada. Pada zaman dimana kenaikan angka kehidupan sangatlah cepat, kita diharuskan untuk cepat tanggap dengan kondisi ini. Permasalahan seperti maraknya pengalihan fungsi lahan pertanian menjadi permukiman yang mengakibatkan menurunnya jumlah hasil produksi beras merupakan bukti bahwa kita belum siap menanggapi perubahan yang begitu cepatnya. Apakah alih fungsi akan terus menjadi solusi hingga seluruh lahan pertanian habis? Lalu akhirnya Indonesia yang merupakan negara agraris ini akhirnya diharuskan untuk mengimpor beras dari negara lain?

Membuat pertanian bertingkat (Vertical) bisa menjadi solusi, dimana lahan yang diperlukan mungkin bisa sama atau bahkan tidak memerlukan lahan seluas pertanian tradisional, namun hasil produksi bisa jauh lebih efektif. Dengan begitu alih fungsi tidak akan jadi masalah karena keperluan lahan pertanian vertikal tidak seluas pertanian tradisional.

\section{Saran}

Pada proyek ini sebenarnya bisa dipelajari lagi bagaimana banjir yang merugikan justru bisa menguntungkan bagi kegiatan didalamnya. Salah satu ide yang ada namun tidak terwujud adalah mengembangkan sebuah sistem berupa flood catcher. Sebuah sistem yang bisa menampung air hujan ataupun banjir yang menggenangi daerah sekitar, yang akan disalurkan melalui drainase yang terhubung dengan tangki air bawah tanah, dimana airnya akan diolah lagi sebelum digunakan untuk keperluan dalam tapak. Air yang ditampung pun cukup banyak dan bisa menjadi sumber air utama dalam tapak selain tangki air PAM.

Jika dilakukan studi lebih mendalam dan waktu yang lebih memungkinkan, ide ini bisa terwujud dan dimasukkan ke dalam rancangan proyek ini.

\section{REFERENSI}

Abbas, W., Riadi, M., Ridwan, I. (2018). RESPON TIGA VARIETAS PADI (Oryza sativa L.) PADA BERBAGAI SISTEM TANAM LEGOWO. Pendahuluan, 1(1), 47.

Badan Pusat Statistik Kabupaten Karawang, Populasi Ternak Menurut Kecamatan dan Jenis Ternak di Kabupaten Karawang, diunduh 3 November 2016, diambil dari: https://karawangkab.bps.go.id/statictable/2016/11/03/106/populasi-ternak-menurutkecamatan-dan-jenis-ternak-di-kabupaten-karawang-2015.html Haifa Group, Crop Guide: Rice Cultivation, retrieved from haifa-group.com: ttps://www.haifagroup.com/rice-0/crop-guide-rice-cultivation

Balai Besar Penelitian Tanaman Padi. (2017). TEKNIK UBINAN PENDUGAAN PRODUKTIVITAS PADI MENURUT SISTEM TANAM. 52 hal.

Didi D. (2017), Cara Menghitung Ubinan/perkiraan Produksi Panen Padi Sawah, diunduh 19 November 2019, diambil dari: cybex.pertanian.go.id/mobile/artikel/80417/CaraMenghitung-Ubinan-perkiraan-Produksi-Panen-Padi-Sawah/;. muhfidzilla, RDTR \& Peraturan Zonasi Kota Karawang, diunduh 2 November 2017, diambil dari: ttps://www.slideshare.net/muhfidzilla/1-pendahuluan-81519452

Dinas Pertanian Kehutanan Perkebunan dan Peternakan Kabupaten Karawang. (2016). LAPORAN KETERANGAN PERTANGGUNGJAWABAN BUPATI KARAWANG, Karawang. 28 hal. Haifa Group, Crop Guide: Rice Cultivation, retrieved from haifa-group.com: https://www.haifa-group.com/rice-0/crop-guide-rice-cultivation R Arif, Kondisi dan Potensi Kabupaten Karawang, diambil dari: http://repository.umy.ac.id/bitstream/handle/123456789/13697/BAB\%20III.pdf?sequ ence $=4$ \&isAllowed $=y$

Kementerian Pertanian Republik Indonesia, 10 Kabupaten Produksi Beras Tertinggi, Mana Saja?, diambil dari: https://www.pertanian.go.id/home/?show=news\&act=view\&id=4419 
Kementrian Pertanian, Direktorat Jendral Peternakan dan Kesehatan Hewan, Direktorat Perbibitan Ternak. (2014). PEDOMAN PEMBIBITAN SAPI PERAH YANG BAIK. 26 hal. muhfidzilla, RDTR \& Peraturan Zonasi Kota Karawang, diunduh 2 November 2017, diambil dari: https://www.slideshare.net/muhfidzilla/1-pendahuluan-81519452

Nuning Widya Herfdimastuti, PENETAPAN BERAT 1000 BUTIR BENIH, diunduh 22 Desember 2020, dari: http://bbppmbtph.tanamanpangan.pertanian.go.id/index.php/berita/541;

R Arif, Kondisi dan Potensi Kabupaten Karawang, diambil dari: http://repository.umy.ac.id/bitstream/handle/123456789/13697/BAB\%20III.pdf?sequ ence=4\&isAllowed $=y$

Tommi., Barus, B., Dharmawan, AH. (2017). PEMETAAN BAHAYA BANJIR LAHAN SAWAH DI KABUPATEN KARAWANG. Pendahuluan, 19(1), 42-44. 